\title{
The Incidence of Cone Epiphyses and Ivory Epiphyses of the Hand in Nigerian Children
}

\author{
HELEN A. SHAW ${ }^{1}$ AND STANLEY P. BOHRER ${ }^{2}$ \\ The Center for Human Growth and Development, University of Michigan, Ann Arbor \\ Michigan 48109 and Department of Radiology, University of Ibadan, Ibadan, Nigeria
}

\author{
KEY WORDS Cone epiphyses - Ivory epiphyses - Hands . \\ Hemoglobinopathies . Nigeria
}

\begin{abstract}
Radiographs of the left hand of 594 children from Ibadan, Nigeria were inspected for skeletal anomalies to determine differences in the incidence of cone and ivory epiphyses for the rich and poor children and differences in incidence for four hemoglobin types. Ivory epiphyses occurred more often in children in the lower socio-economic class and children with hemoglobin AA. The cone epiphyses observed in $\mathrm{Hb} \mathrm{SS}$ children were primarily a result of bone infarcts, while cones in children of other hemoglobin types appeared to be normal variants. The incidence of ivory epiphyses was higher in the Nigerian children than in American black children in the Ten-State Nutrition Survey. The incidence of cone epiphyses was much lower than those reported for other normal populations.
\end{abstract}

The sample under discussion is primarily from a longitudinal growth study of Nigerian children of the Yoruba tribe conducted by the Institute of Child Health (ICH) of the University of Ibadan in Ibadan, Nigeria (Janes, '70, '74, '75). Hemoglobin types represented in this group are AA, AS and AC. The children are from Ibadan and range in age from birth through 15 years. The sample is comprised of two distinctly different socio-economic groups. The first is an elite group consisting of children from well-to-do, educated, mostly professional families who live in modern houses with indoor plumbing and cooking facilities; the family unit is monogamous. The second group of children is from more traditional, often polygynous households which have no plumbing or modern cooking facilities; they have very little formal education and are generally quite poor.

The elite children received no medical aid from the ICH while the poor children irregularly received the anti-malarial nivaquine (to be taken when needed) and powdered milk or other food. What anti-malarials the children did receive very likely went to whichever family member happened to need them at the time and not necessarily to the child for whom they were intended. It was assumed that elite children received anti-malarials when needed from their family doctor or some other source.

Children with hemoglobin types SS and SC were selected during routine clinic and hospital visits. These groups are hetergeneous socio-economically and range in age from birth to 64 years. Radiographs of these individuals were, for the most part, taken before they received folic acid treatment. The total data base (ICH plus SS and SC) at the time of this study numbered 666 , of which 594 were between the ages of 2.5 and 16.5 years, inclusive. Between these ages, most or all of the 19 epiphyses of the hand are present and have not as yet fused with the diaphyses. Table 1 gives sample sizes for subgroups in the study population. No individual was represented more than once in the study population.

Hand-wrist radiographs of the children were obtained by Doctor Bohrer while working with Doctor Janes on the ICH project. During analysis of the radiographs, a high incidence of minor skeletal anomalies was noticed; carpal fusions (primarily of the triquetral and

\footnotetext{
${ }^{1}$ Present address: 1727 North Dayton Street, Chicago, Illinois 60614.

${ }^{2}$ Present address: Programa HOPE, Apartado Aereo \#28-79, Cartagena, Columbia, South Anerica.
} 


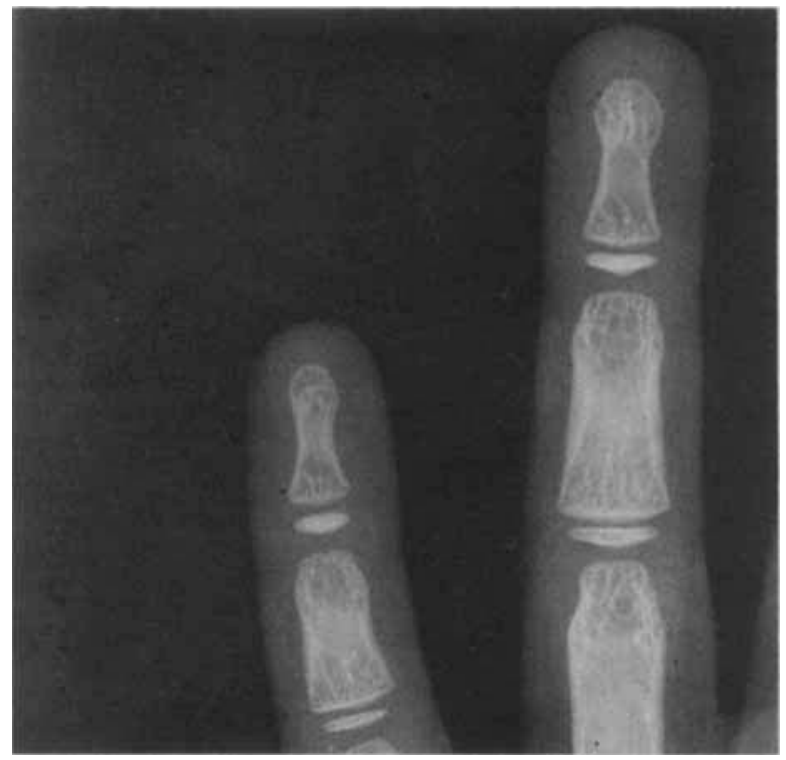

Fig. 1 These ivory epiphyses were observed in the distal epiphyses of a poor male Nigerian child with hemoglobin type AS. Note the even density of the epiphyses and their lack of trabecular structure. The appearance of having been carved from ivory gives them their name.

TABLE 1

Sample sizes for the study

\begin{tabular}{lrrrrrrrrrrrr}
\hline & \multirow{2}{*}{$\begin{array}{c}\text { Total } \\
\text { sample }\end{array}$} & SS & SC & AA & AS & AC & & AA & AS & AC & $?^{1}$ \\
\hline Group N & 594 & 53 & 9 & 197 & 70 & 23 & & 169 & 64 & 7 & 2 \\
Cone epiphyses & 16 & 9 & 1 & 2 & 1 & 1 & 2 & 0 & 0 & 0 \\
Ivory epiphyses & 29 & 4 & 0 & 16 & 2 & 2 & 2 & 1 & 0 & 2 \\
\hline
\end{tabular}

${ }^{1}$ Hemoglobin type unspecified at time of analysis.

lunate), brachymesophalangia-5, notching of the distal tufts and in particular ivory epiphyses and cone epiphyses, were observed. These latter two anomalies are of interest because of their distribution and incidence in the Nigerian children.

It has previously been noted that both cone and ivory epiphyses occur in normal and abnormal children (Giedion, '65, '67, '76; Hertzog et al., ' 68 ; Rondon de Iturriza and Tanner, '69; Saldino and Mainzer, '71; Kuhns et al., '73; Mathiasen, '73). The incidence of both cone and ivory epiphyses is higher in children who are delayed in skeletal maturation and/or genetically abnormal (Giedion, '65, '67; Rondon de Iturriza and Tanner, '69; Kuhns et al., '73; Poznanski, '74). In terms of skeletal maturation, as indicated by the secondary ossification centers of the hand, the poor $\mathrm{Ni}$. gerian children lagged behind the TannerWhitehouse II standards for British children (Tanner et al., '75), while the elite children were advanced when compared to the British children. The children with hemoglobin types SS and SC also evidenced delayed skeletal maturation. The study population was subdivided by hemoglobin types on the suspicion that hemoglobin type in an endemic malarial area affects skeletal maturation and overall health status and thus indirectly influences the incidence of ivory and cone epiphyses. The predisposition of persons with hemoglobin types SS and SC to bone infarct and the occurrence of delayed skeletal maturation in these persons (Whitten, '61; Ashcroft et al., '72; Serjeant and Ashcroft, '73) also indicated the probability of high incidences of cone and ivory epiphyses in the affected populations. 


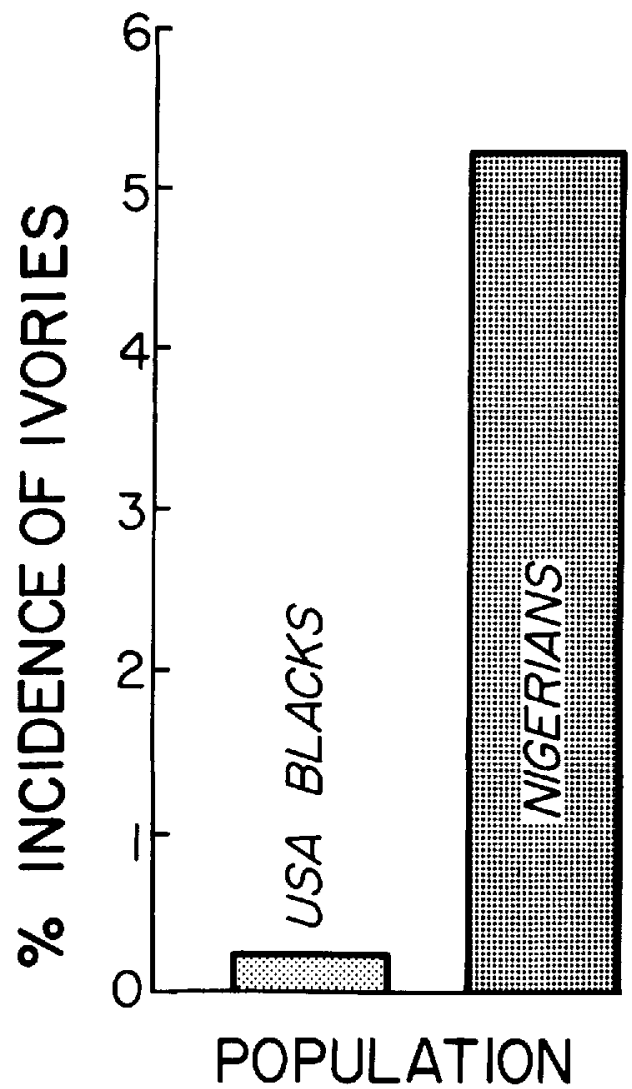

Fig. 2 The incidence of ivory epiphyses of the hand is illustrated for Nigerian children and U.S. black children. The Nigerian's occurrence rate is 20 times higher than that of the American blacks.

\section{IVORY EPIPHYSES}

Ivory epiphyses are very dense and usually noticeably smaller than corresponding normal epiphyses in the same individual. No trabecular structure can be seen and the density is even throughout the epiphysis (fig. 1). Dense appearing, sliver-like epiphyses which are just beginning to ossify are not classed as ivory epiphyses. As yet no ivory epiphysis has been studied histologically and thus their exact composition is unknown. They do seem to be a transitory phenomenon in that when followed in serial radiographs, their density gradually disappears and the epiphysis becomes normal in appearance, eventually fusing with the diaphysis and giving little or no indication of its previous anomalous form.

Macdonald et al. ('60) first used the term ivory epiphysis to describe dense epiphyses in Cockayne's syndrome. Rondon de Iturriza and
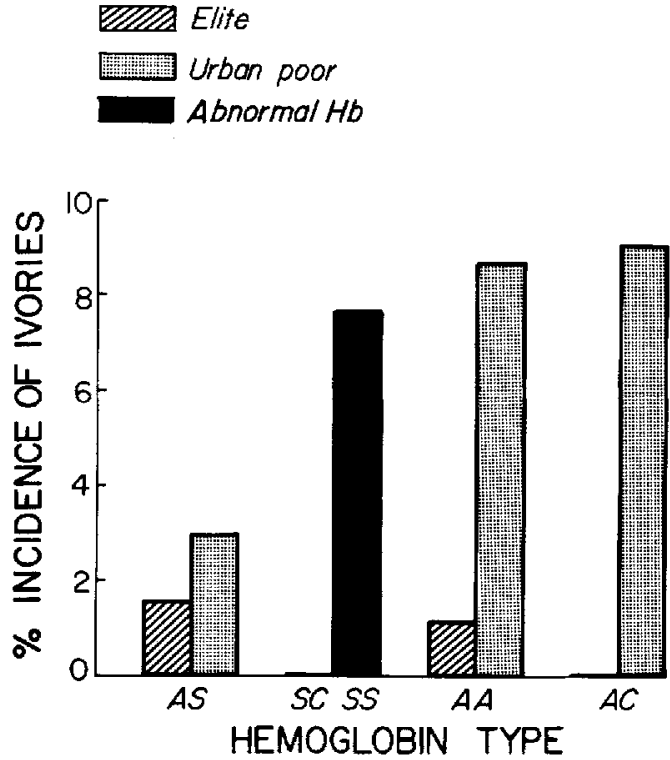

Fig. 3 The incidence of ivory epiphyses in different hemoglobin types and social classes is illustrated. Note the high incidence of ivory epiphyses in poor children as compared to the elite and the high incidence in hemoglobin type $\mathrm{AC}$ relative to type AS. The dotted bars represent poor children, the diagonal bars elite children, and the solid bars children with hemoglobin types SC and SS.

Tanner ('69), and later Kuhns et al. ('73) were the first to describe ivory epiphyses in otherwise normal children. Kuhns et al. ('73) was the only study to include children of African ancestry. These were American black children who participated in the Ten-State Nutrition Survey of 1968-1970. These children showed an incidence for ivory epiphyses of $0.3 \%$ in boys and $0.2 \%$ in girls, ranging in age from 2 to 13 years. The rate for the total population of 3,570 children was $0.3 \%$. This sample was primarily low income, but fairly well nourished. The incidence of ivory epiphyses in the Nigerian children was $5.0 \%$, or almost 20 times that of American black children (fig. 2). In the American children, asymptomatic ivory epiphyses were associated with delay in skeletal maturation averaging two years behind age and sex matched controls from the same study without ivory epiphyses (Kuhns et al., 73). The Nigerian children with ivory epiphyses also showed maturational delay, but it averaged only one year behind controls matched for age, sex, social class, and hemoglobin type.

When compared across class lines, the poor children had a significantly higher incidence 


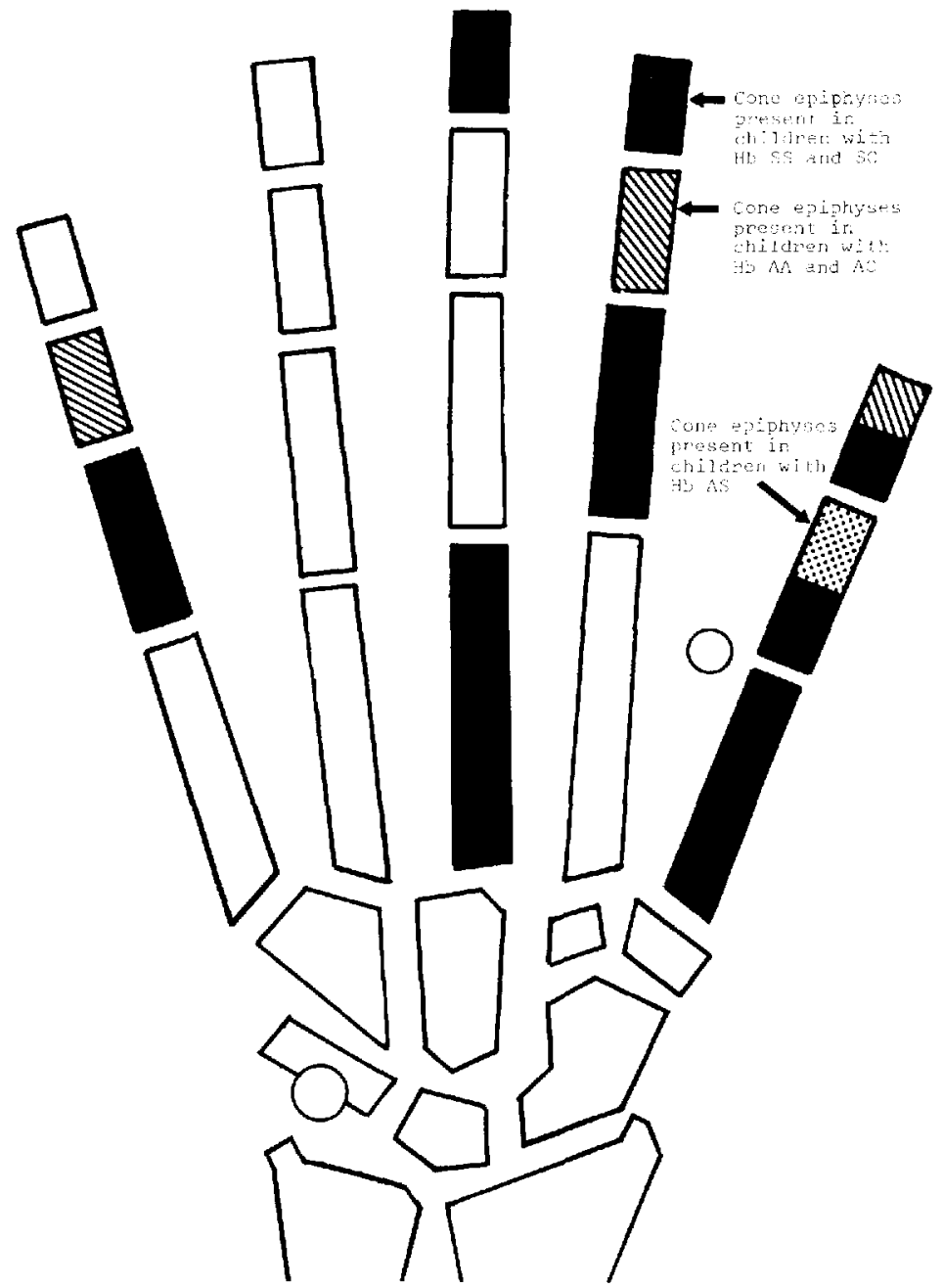

Fig. 4 The distribution of cone epiphyses of the hand in Nigerian children is given. Solid black areas indicate the occurrence of cone epiphyses in children with hemoglobin types SS and SC; areas with dots indicate children with hemoglobin type AS, while diagonal lines indicate hemoglobin types AA and AC.

of ivory epiphyses than did the elite children, $7.2 \%$ versus $2.1 \%$ with a chi square of 6.528 ( $\mathrm{p}$ $<0.01$ ). In American black children, ivory epiphyses occurred in distal phalanges II through $\mathrm{V}$, but in Nigerian children the distribution of ivory epiphyses differed in the two socio-economic groups. Ivory epiphyses were observed in elite children only in distals II and $\mathrm{V}$, while in poor children they occurred in distals II through $\mathrm{V}$. This finding may simply be due to the low incidence of ivory epiphyses in elite children relative to poor children.

The incidence of ivory epiphyses did not differ significantly between the hemoglobin types, and no differences were found between these groups (within social class) for bone mineral content measured in metacarpal II (Garn et al., '71) or Tanner-Whitehouse II bone age. The incidence of ivory epiphyses in children with $\mathrm{Hb}$ AS was $2.2 \%$; in children with $\mathrm{Hb} \mathrm{AA}$ the incidence was $4.9 \%$; and in children with $\mathrm{Hb} \mathrm{AC}$ it was $6.7 \%$. No children with $\mathrm{Hb} \mathrm{SC}$ had ivory epiphyses. Among children with $\mathrm{Hb}$ SS the incidence of ivory epiphyses was $7.5 \%$, but this was not significantly different from the other hemoglobin types (chi square $=3.589$ ).

When one considered both social class and 


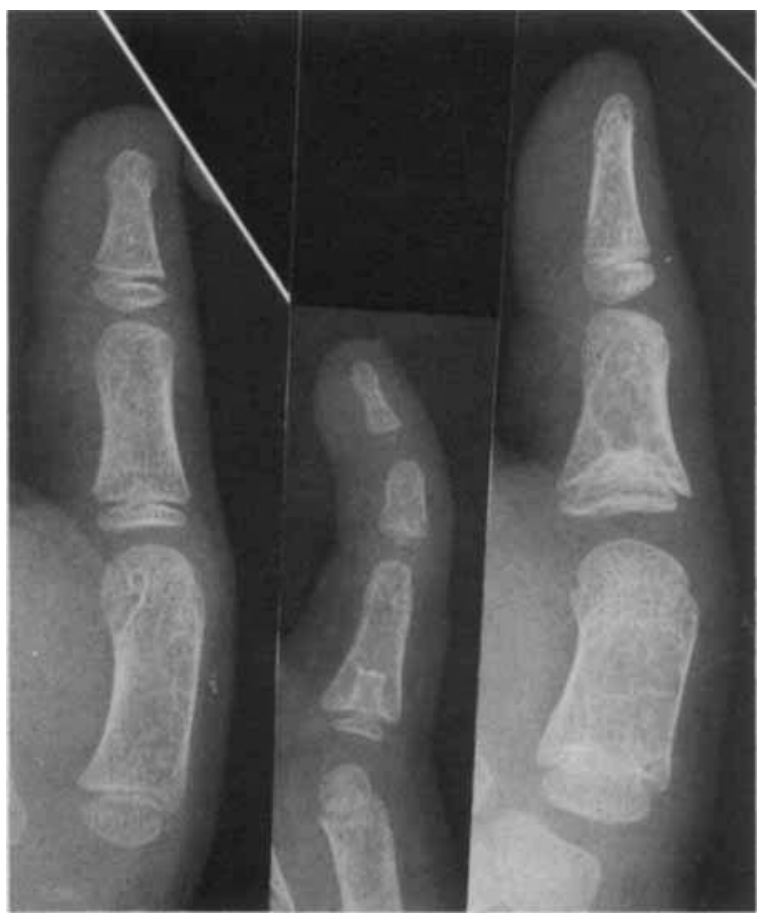

Fig. 5 Examples of cone epiphyses observed in Nigerian children are shown. A mild cone is seen on the left in proximal I. In the middle the typical cone acquired through bone infarct is seen in proximal I. On the right squared off cones usually seen in children with hemoglobin SS and SC appear in proximal I and metacarpal I.

hemoglobin type, poor children with hemoglobin types AA and AC had the highest incidence of ivory epiphyses $-8.1 \%$ and $8.7 \%$ respectively (fig. 3). For poor children with $\mathrm{Hb}$ AS the incidence was only $2.9 \%$. No elite children with $\mathrm{Hb} \mathrm{AC}$ had ivory epiphyses, and the incidence for types AA and AS were about equal $-1.2 \%$ and $1.6 \%$ respectively - for this well nourished, healthy group. There were no significant chi squares for any comparisons of normal hemoglobin types.

\section{CONE EPIPHYSES}

A cone epiphysis occurs when the natural calcification pattern of the diaphysis and its metaphysis is disturbed. Usually the disturbance is manifested in the center of the epiphysis and metaphysis as the central cartilage of the epiphysis progresses further than the peripheral cartilage. The result is an indentation, and in some instances a splaying, of the metaphysis and a protuberance of the epiphysis into the indentation. The growth disturbance may be congenital or acquired through trauma such as frostbite or bone infarct ( $\mathrm{Poz}$. nanski, '74).

In a bone infarct, the blood supply is drastically reduced and damage occurs not only at the metaphysis, but deep into the shaft, forming a translucent, squared off pocket of necrotic tissue. The epiphysis, whose blood supply has not been hindered, reacts with an increase in growth into the damaged area, forming a cone epiphysis. In some cases the growth disturbance is great and the resulting cone is quite obvious, while in other cases the disturbance is relatively mild and the cone barely noticeable (Barton and Cockshott, '62; Cockshott, '63; Watson et al., '63; Reynolds, '65, '66; Greenfield, '75).

Giedion ('65, '67, '76) was the first to set forth a typology for cone epiphyses, where they occur, and their distribution among normal and abnormal children. Cone epiphyses in clinically normal children from several western countries usually occurred in the distal phalanx of the thumb, the middle phalanx of the fifth finger, and the distal phalanx of the third finger (Giedion, '67; Hertzog et al., '68; 


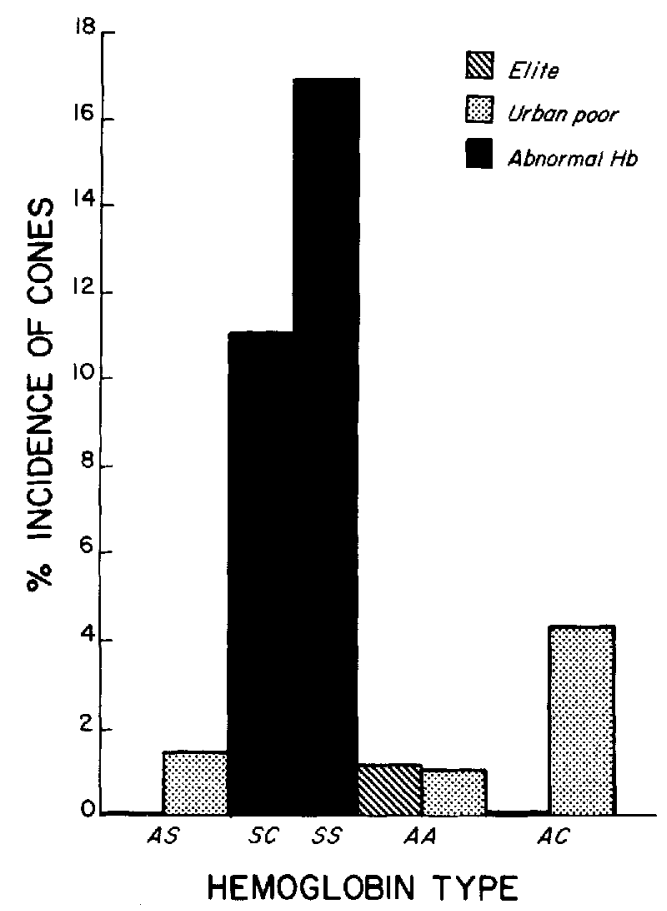

Fig. 6 The incidence of cone epiphyses of the hand in Nigerian children is given. Note the high incidence of cone epiphyses in hemoglobin type $\mathrm{AC}$ relative to type $\mathrm{AS}$ and the very high incidence of cones in children with hemoglobin types SS and SC.

Rondon de Iturriza and Tanner, '69). Giedion ('67) also observed cones at middle II and distals II, IV, and V. Hertzog et al. ('68) observed at least one cone epiphysis at metacarpal $I$ in normal children, but this is a very rare occurrence. For most countries, the incidence of cone epiphyses at the two most common sites (middle $\mathrm{V}$ and distal $\mathrm{I}$ ) averages $2.0 \%$ in boys and $8.0 \%$ in girls or about $4.0 \%$ overall.

\section{RESULTS AND DISCUSSION}

The incidence of cone epiphyses in the Nigerian children was $2.7 \%$ for the total population aged 2.5 to 16.5 years, regardless of socio-economic class and hemoglobin type. There was no sex difference. Cone epiphyses in these Nigerian children were primarily acquired rather than congenital and were due to bone infarcts in children with hemoglobin types SS and SC. Their distribution in the hand was somewhat random, in that a bone infarct may occur in any metacarpal or phalanx of any digit, and may or may not disrupt growth sufficiently to cause a cone epiphysis.
Nonetheless, these acquired cone epiphyses occurred only at sites listed by Giedion as being expected in abnormal children or at sites not listed by him at all (fig. 4). These acquired cones occurred at metacarpals I and III and at proximals I, II and V. Cone epiphyses observed in the distal phalanges of children with $\mathrm{Hb}$ SS appeared to be normal variants which occur at such sites. In children with hemoglobin types AA, AS, and $\mathrm{AC}$, the cone epiphyses observed were usually normal variants and occurred at the expected sites: distal I, middle II and middle V. One child with $\mathrm{Hb}$ AS had a mild cone epiphysis at proximal I, but this was the only deviation from the expected.

An attempt was made to type all the observed cone epiphyses according to Giedion's classification, but this proved unsatisfactory with the acquired cones, though type $38 \mathrm{~A}$ (Giedion, '76) was seen in two cases (fig. 5, center). It was found, however, that most cone epiphyses in children with hemoglobin types SS and SC were similar; they resembled infarct damage previously reported in other long bones such as the tibia and femur (Bohrer, '70). The cone epiphyses in these children were usually distinguished by a relatively large, squared off area in the metaphysis and a moderately large cone-shaped epiphyses protruding into the metaphysis. Cone epiphyses observed in children with other hemoglobin types were normal variants, with the exception of one boy with $\mathrm{Hb} \mathrm{AC}$ who had an odd cap-shaped epiphysis at middle II.

The incidence of cone epiphyses in children with $\mathrm{Hb}$ SS was $17.0 \%$ while children with $\mathrm{Hb}$ SC had an incidence of $11.1 \%$ (fig. 6), the Ns being significantly higher than those obtained for other hemoglobin types (chi square = $49.113, p<0.001$ ). Of the other hemoglobin types, only $\mathrm{AC}$ had a relatively high incidence of cone epiphyses - $3.3 \%$ or one child in 30 . Both hemoglobin types AA and AS had incidences around $1.0 \%$. Four poor boys and two elite girls had cone epiphyses, making the incidence for the poor population $1.4 \%$ and for the elite population $0.8 \%$. By redefining the total population to exclude children with hemoglobin types SS and SC, the incidence of cone epiphyses dropped from $2.7 \%$ to $1.1 \%$. Ignoring the acquired cones and looking only at the common normal variants dropped the incidence of cone epiphyses in SS and SC children to $3.2 \%$. 


\section{SUMMARY AND CONCLUSION}

We have observed a very high incidence of ivory epiphyses, which are indicative of delayed skeletal maturation, in the chronically malnourished and sickly poor children and in children with sickle cell anemia. It appears that the high incidence of ivory epiphyses in Nigerian children, which is 20 times higher than that for American children of African ancestry, is directly related to poor nutrition and health, though genetic factors also appear to be an influence. Cone epiphyses, which are indicative of growth disturbances, are uncommon in the Nigerian children, but the incidence is deceiving until one accounts for hemoglobin type and cones acquired through bone infarct. The incidence of cone epiphyses for children with hemoglobin types SS and SC is exceedingly high but, because of infarct, is to be expected. By leaving these children out of the calculations, the incidence for the total population is well below figures given for other normal populations.

\section{ACKNOWLEDGMENTS}

Doctor M. Janes kindly allowed us to study her cases. Doctor L. R. Kuhns was consulted in the deliniation of ivory epiphyses. Doctor A. K. Poznanski assisted in typing the cone epiphyses. Doctor A. Giedion kindly wrote us his assessment of the cone epiphyses found in our SS and SC cases. P. A. Olowa and J. A. Adewole of Ibadan provided technical assistance. Doctor S. M. Garn provided the time and facilities needed to undertake this study.

Funds for computer analysis of the data came in part from NIH grant number HD07134. Funds for studies of the children conducted in Nigeria were provided by Watson and Sons (Electro-Medical) Nigeria LTD.

\section{LITERATURE CITED}

Ashcroft, M. T. G. R. Serjeant and P. Degai 1972 Heights, weights, and skeletal age of Jamaican adolescents with sickle cell anaemia. Arch. Dis. Child., 47: 519-524.

Barton, C. J., and W. P. Cockshott 1962 Bone changes in hemoglobin SC disease. Am. J. Roentgenol., 88: 523-532. Bohrer, S. P. 1970 Acute long bone diaphyseal infarets in sickle cell disease. Br. J. Radiol., 43: 685-697.
Cockshott, W. P. 1963 Dactylitis and growth disorders. Br. J. Radiol., 36: $19-26$.

Garn, S. M., A. K. Poznanski and J. M. Nagy 1971 Bone measurement in the differential diagnosis of osteopenia and osteoporosis. Radiology, 100: 509-518.

Giedion, A. 1965 Cone-shaped epiphyses (CSE). Ann. Radiol., 8: 135-145.

1967 Cone-shaped epiphyses of the hand and their diagnostic value. The tricho-rhino-phalangeal syndrome. Ann. Radiol., 10: 322-329.

- 1976 Acrodysplasias. Clin. Orthop. Rel. Res. 114: $107-115$.

Greenfield, G. B. 1975 Radiology of Bone Diseases. Second ed. J. B. Lippincott Company, Philadelphia, pp. 49-67.

Hertzog, K. P., S. M. Garn and S. F. Church 1968 Coneshaped epiphyses in the hand. Invest. Radiol., 3: 433-441.

Janes, M. D. 1970 The effect of social class on the physical growth of Nigerian Yoruba children. Bull. Intern. Epidemiol. Assoc., 20: 127-135.

1974 Physical growth of Nigerian Yoruba children. Trop. Geogr. Med., 26: 389-398.

1975 Physical and psychological growth and development. Evir. Child Health, 21: 26-30.

Kuhns, L. R., A. K. Poznanski, H. A. S. Harper and S. M. Garn 1973 Ivory epiphyses of the hand. Radiology, 109: 643-648.

Macdonald, W. B., K. D. Fitch and I. C. Lewis 1960 Cockayne's syndrome. An heredo-familial disorder of growth and development. Pediatrics, 25: 997-1007.

Mathiasen, M. S. 1973 Determination of bone age and recording of minor skeletal hand anomalies in normal children. Dan. Med. Bull, 20: 80-85.

Poznanski, A. K. 1974 The Hand in Radiologic Diag. nosis. W. B. Saunders Company, Philadelphia, pp. 104 $107,110-116,475-477,487$.

Reynolds, J. 1965 The Roentgenological Features of Sickle Cell Disease and Related Hemoglobinopathies. Charles C Thomas, Springfield, pp. 9, 37-39, 129-131.

1966 A re-evaluation of the "fish vertebra" sign in sickle cel] hemoglobinopathy. Am. J. Roentgenol., 97. 693-707.

Rondon de Iturriza, J., and J. M. Tanner 1969 Cone-shaped epiphyses and other minor anomalies in the hands of normal British children. Pediatrics, 75: 265-272.

Saldino, R. M., and F. Mainzer 1971 Cone-shaped epiphyses (CSE) in siblings with hereditary renal disease and retinitis pigmentosa. Radiology, 98: 39-45.

Serjeant, G. R., and M. T. Ashcroft 1973 Delayed skeletal maturation in sickle cell anemia in Jamaica. Johns Hopkins Med. J., 132: 95-102.

Tanner, J. M., R. H. Whitehouse, W. A. Marshall, M. J. R Healy and H. Goldstein 1975 Assessment of Skeletal Maturity and Prediction of Adult Height (TW2 Method). Academic Press, New York.

Watson, R. J., H. Burko, H. Megas and M. Robinson 1963 The hand-foot syndrome in sickle-cell disease in young children. Pediatries, 31: 975-982.

Whitten, C. F. 1961 Growth status of children with sickle-cell anemia. Am. J. Dis. Child., 102: 101-110. 